BRINGING 'PLACE' BACK IN: REGIONAL CLUSTERS, PROJECT GOVERNANCE, AND NEW PRODUCT OUTCOMES

\author{
Paul Tracey \\ Judge Business School \\ University of Cambridge \\ Trumpington $\mathrm{St}$ \\ Cambridge, UK \\ CB2 $1 \mathrm{AG}$ \\ Tel: +44 1223760471 \\ E-mail: p.tracey@jbs.cam.ac.uk \\ Jan B. Heide \\ University of Wisconsin-Madison $^{1}$ \\ 3106 Grainger Hall \\ 975 University Avenue \\ Madison, WI 53706 \\ Tel: +1 6082625224 \\ Email: jheide@bus.wisc.edu \\ Simon J. Bell \\ Faculty of Business and Economics \\ 198 Berkeley St \\ University of Melbourne \\ Melbourne, VIC 3010 \\ Australia \\ Tel: +61383441920 \\ Email: simonb@unimelb.edu.au
}

\footnotetext{
${ }^{1}$ Professorial Fellow, Department of Management and Marketing, University of Melbourne, Fellow in Marketing, Cambridge Judge Business School, University of Cambridge.
} 


\title{
BRINGING 'PLACE' BACK IN: REGIONAL CLUSTERS, PROJECT GOVERNANCE, AND NEW PRODUCT OUTCOMES
}

\begin{abstract}
We examine new product outcomes in the context of regional clusters. Based on past research on marketing relationships, clusters, and social networks, we propose that the overall configuration of a cluster helps promote particular governance practices among its members. These practices have distinct value-creating properties, and when they are brought to bear on a specific new product development project within a cluster, they promote performance outcomes like product novelty and speed to market. Ultimately, these performance effects are reinforced by the configuration of the cluster itself. In general, we propose that new product outcomes follow from complex interactions between a cluster's macro-level configuration and its micro-level governance processes. More broadly, our framework points to the importance of geographical variables and to the role of "place" in marketing decision-making.
\end{abstract}

Key words: Inter-firm relationships, regional clusters, inter-firm governance, transaction cost theory, social network theory, and new product development. 
Relentless innovation, and the new products to which it gives rise, underpins long-term marketing performance. New product failure rates, however, remain stubbornly high, a fact that has motivated both scholars and practitioners to unearth the drivers of successful product development. Historically, researchers have focused on internal drivers of product success such as the nature of a firm's overall strategy (e.g., Gatignon and Xuereb 1997), its planning processes (e.g., Moorman and Miner 1998), its organizational structure (e.g., Olson et al. 1995), and its particular development activities (Griffin 1997; Sethi et al. 2001). Increasingly, however, scholars have expanded their focus to consider how innovation processes involve outside partners and are managed across organizational boundaries (Fang 2011; Rindfleisch and Moorman 2001; Sivadas and Dwyer 2000; Tellis et al. 2012).

This shift in orientation reflects a growing realization that marketing practices, including new product development (NPD), are carried out within inter-firm networks (Achrol and Kotler 1999; Wuyts and Van den Bulte 2012). We focus on a particular category of networks; those that are spatially confined and whose members are geographically co-located or clustered. Such networks are of considerable interest to marketers because of their presumed ability to promote innovation and NPD. Surprisingly, however, despite long and sustained research interest in other academic disciplines like geography (e.g., Gertler 1995), economics (e.g., Krugman 1991), strategy (e.g., Porter 2000), and organization theory (e.g., Tallman and Phene 2007), there has been, with some notable exceptions (e.g., Ganesan et al. 2005), few systematic attempts in marketing to explore the role of regional clusters. The lack of attention is particularly surprising given marketing's historical concern with 'place' (McCarthy 1960) which suggests that geographical variables and reasoning are of fundamental importance. 
While geographical clustering is sometimes portrayed as a panacea for innovation (Martin and Sunley 2003), we note that clusters vary considerably with respect to their innovation outcomes. Although there are numerous accounts of successful clusters such as Silicon Valley in California (Kenney 2000) and Baden-Württemberg in southwest Germany (Fuchs and Wassermann 2005), there is also evidence that clustering does not automatically lead to improved performance. In fact, many well-known clusters, for example the "multimedia super corridor" in Malaysia, have fallen short of initial expectations (Ramasamy et al. 2004). Others, such as the biotechnology cluster in the Lombardy region of Italy, have been deemed outright failures (Orsenigo 2001).

The mixed body of evidence raises questions about the specific manner in which clusters promote performance, including new product success. In much of the cluster literature, consistent with its roots in economic geography, performance is assumed to follow from the phenomenon of clustering per se; namely from a given cluster's overall structure or configuration (e.g., Markusen 1996; Romanelli and Khessina 2005). Recent research, in contrast, has focused on a cluster's internal processes. Specifically, researchers (e.g., Atherton and Johnston 2008; Bell et al. 2009) have suggested that performance follows from the particular way in which individual cluster transactions are governed.

The emerging theoretical view of clusters is a complex and nuanced one, where performance is seen as a function of both a cluster's configuration and its internal governance processes. At the same time, despite increasing acceptance of such a perspective, as evidenced by assertions that "clustered firms are situated in both geographic and social structural spaces" (Whittington et al. 2009, p. 90), the specific roles of cluster configuration and process, and how these roles ultimately impact performance, remain elusive. 
We focus on two particular roles of cluster configuration. First, we draw on social network theory (Antia and Frazier 2001; Provan et al. 2007; Wuyts and Van den Bulte 2012) to propose that certain cluster configurations promote the emergence of particular governance practices among its members in the first place. Specifically, dense clusters promote relational governance (Lusch and Brown 1996; Macneil 1980), while centralized clusters give rise to hierarchical governance (Mooi and Ghosh 2010; Stinchcombe 1986). These governance practices, when brought to bear on a given product development project, are associated with particular performance outcomes. Specifically, we argue that relational governance has the ability to both identify and help commercialize truly novel products, while hierarchical governance helps products' speed to market.

Second, beyond promoting the emergence of particular governance practices ex ante, we propose that a cluster's overall configuration will support their performance effects ex post. Specifically, relational governance's ability to promote product novelty is enhanced within dense clusters, while hierarchical governance's ability to promote speed to market is enhanced within centralized clusters. In other words, we posit that matches between cluster configuration and project-level governance have specific value-creating properties. Conversely, we propose that mismatches between cluster configuration and project governance can produce transaction costs that undermine new product outcomes. In general, we develop a complex and nuanced account of how new product outcomes in a cluster context come about, where a single variable like cluster configuration actually plays multiple roles.

With this framework, we seek to make five contributions. First, we show the relevance of clustering to a key marketing phenomenon. Theoretically, we propose a macro-level perspective 
on new product development; a perspective which remains underutilized in marketing, as evidenced by Tellis' (2013) recent review.

Second, we add to the existing literature on inter-firm governance. Historically, the emphasis in this literature has been on the micro-level mechanisms themselves (e.g., Wathne and Heide 2000). Emerging research, however, shows that the effects of governance mechanisms depend on the larger contexts in which they are deployed (Antia and Frazier 2001; Wuyts and Van den Bulte 2012). We add to past research by proposing specific constellations between 1) two different governance mechanisms (relational, hierarchical) and 2) two different cluster configurations (density, centralization). Theoretically, our framework points to larger systems of governance, where matches and mismatches between mechanisms and configuration impact performance.

Third, we provide particular insights into relational governance. As noted by Gibbons and Henderson (2012), such governance practices are both common and important to firms. It is less than clear, however, how relational practices actually originate. In fact, researchers have argued that relational governance "can't be deployed at will” (Ghosh and John 2012). Our framework suggests that cluster density is a particular driver of relational governance.

Fourth, from a practical standpoint we point to an important source of efficiency in new product development. An NPD project, such as the development of a new car model, involves multiple collaborators that span upstream component design and manufacturing as well as downstream distribution. To the extent that the relevant parties, by virtue of their cluster membership, subscribe to common governance practices, they will benefit from reduced ongoing transaction costs that may otherwise harm new product performance. 
Fifth, our framework contributes to the original cluster literature and to economic geography more broadly. Historically, the literature on clusters has tended to focus exclusively on the early part of the innovation process, namely idea generation. We propose that the implications of clustering go beyond this initial stage. In fact, the ability to bring common governance practices to bear on a new project offers coordination benefits which affect the entire product development process; from the initial idea and the "fuzzy front end" to final commercialization.

The paper is organized in the following fashion: In the section below, we establish some basic cluster concepts and suggest possible linkages with specific marketing outcomes. Next, we present our conceptual framework and research propositions. The final section articulates our contributions and offers suggestions for marketing practice and future research.

\section{Clusters and Performance Outcomes}

We follow Porter (1998, p. 197) in defining clusters as "geographic concentrations of interconnected companies... and associated institutions". He and others make the distinction between a cluster's vertical dimensions (i.e., customers and suppliers) and its horizontal dimensions (i.e., competitors and firms that produce complementary products and provide specialized services such as venture capital). More developed clusters often include actors such as research-intensive universities, trade bodies, and professional associations. While there continues to be much debate and disagreement in the literature, Porter's conception of clusters has become widely used in part because it synthesizes ideas from prominent overlapping schools of thought within economic geography (Martin and Sunley 2003), including the work on "new industrial spaces" (Scott 1988), "regional innovation systems" (Edquist 1997), and "industrial districts" (Beccatini 1989). Although there are substantive differences between these 
perspectives, they each view clusters as characterized by three basic features (Asheim et al. 2013; McKendrick et al. 2000; Tallman et al. 2004).

First, while they do not have fixed borders, clusters comprise members co-located in an identifiable location, although the geographical scale of the location may vary significantly. For example, Porter draws on the sprawling agribusiness cluster on the West Coast of the US that spans state boundaries, and the media cluster in New York that is confined to part of lower Manhattan, to illustrate his arguments. Second, clusters comprise members that interact with and are related to one another; a firm that is co-located with other similar firms in a given place but does not transact with them is not considered a member of a particular cluster. This means that cluster membership involves the exchange of resources, including physical and human assets, with other actors in the cluster. Third, cluster members have a shared sense that they are part of the cluster; a common feeling that they are situated in a particular community. In other words, to belong to a cluster constituent firms need to identify as cluster members and hold what Romanelli and Khessina (2005) call a "regional identity". In the marketing literature, Achrol (1997) refers to this in terms of a feeling of "belongingness". Because of these variations in scope, the demarcation of cluster boundaries is seldom straightforward. Indeed, a basic assumption in the literature is that the confines of a given cluster are continually evolving (Dicken and Malmberg 2001; Eisingerich et al. 2010; Feser and Bergman 2000; O’Donoghue and Gleave 2004).

A considerable body of research has focused on various aspects of performance in clusters, in particular on innovation outcomes. Specifically, performance follows from utilizing knowledge and other intangible resources to create and market novel products and services (Arikan 2009; Owen-Smith and Powell 2004; Tallman et al. 2004; Whittington et al. 2009). 
In developing our conceptual framework, we rely on the general conceptualization of performance as rooted in innovation outcomes. However, our conceptualization differs from past work in two distinct ways: First, previous research has tended to apply the notion of innovation to a cluster as a whole. While such a focus is consistent with the idea of a "region" as a competitive unit in its own right (Bristow 2005; Cooke 2001), it also obscures potential insights made possible by considering performance at the level of individual NPD projects. Second, while we remain true to the general emphasis in past research on innovation, we draw on recent research in marketing (Ganesan et al. 2005; Rindfleisch and Moorman 2001) to provide a more fine-grained conceptualization which encompasses two different new product outcomes, namely product novelty and speed to market. We define novelty as the extent to which the focal products differs from competing alternatives in a way that is meaningful to customers (Dewar and Dutton 1986; Fang 2011; Simon 1985). Speed refers to the elapsed time from the initial idea stage of the process to the actual market launch (Fang 2011; Rindfleisch and Moorman 2001).

\section{New Product Development Projects and Governance}

Our unit of analysis is a particular NPD project, which can be defined as a temporary organizational entity used to integrate activities and people across different organizational and disciplinary domains with the objective of launching a specific product (Morris et al. 2011). In practice, a project involves the entire conversion process from an initial idea to a commercialized product (e.g., Chandy et al. 2006; Fang 2011). For instance, launching a new car model requires managing the interfaces between up- and downstream parties that span component supply, design, manufacturing, marketing, sales, and distribution (Adler 1995; Terwiesch et al. 2002).

While successful conversion depends fundamentally on integration between the relevant parties, past research has pointed to various barriers or sources of "friction" (Arrow 1969) that may compromise favorable outcomes (Griffin and Hauser 1996; Staudenmayer et al. 2005). 
Overcoming these barriers requires deliberate relationship governance across the relevant interfaces to ensure "order" (Commons 1931). The challenge goes beyond managing the technical interfaces per se (e.g., between design and manufacturing); the larger task involves a "mapping between the product architecture and the organizational structure" (Sosa 2007).

Past research (e.g., Geyskens et al. 2006; Poppo and Zenger 2002; Wathne and Heide 2004) has shown that purposeful governance can take different forms. Specifically, researchers have made a conceptual distinction between 1) relational governance mechanisms which are rooted in informal norms and implicit understandings (Gibbons 2010; Macneil 1981), and 2) hierarchical governance mechanisms like contractual arrangements which establish decision rights and specify acceptable behaviors (Grossman and Hart 1986; McKendrick et al. 2000; Mooi and Ghosh 2010). The central premise of relational governance is to align parties' preferences ex ante, while hierarchical governance involves imposing restrictions which regulate their on-going interaction (Bradach and Eccles 1989; Ouchi 1980). In the terminology of intraorganizational coordination (Burns and Stalker 1961; Gerwin 2004; Thompson 1967), the latter involves mechanistic "planning", in contrast with the organic "mutual adjustment" that defines relational governance.

Importantly, while both strategies involve purposeful governance, they possess different properties. As a consequence they can be expected to have different antecedents, some of which pertain to the nature of the larger cluster in which the focal firms are located. We turn to this question next.

\section{Cluster Configuration and NPD Project Governance}

Our conceptual framework is shown in Figure 1. Its key exogenous influences are a cluster's aggregate properties or its configuration. We draw on network theory - in particular 
research that takes a whole-of-network ${ }^{2}$ perspective to the study of organizations (e.g., Baum et al. 2003; Provan et al. 2007; Provan and Kenis 2008). We describe a cluster in terms of its density (the overall connectedness among organizations within a network) and centralization (the extent to which one or a few organizations are more centrally located than others). Below, we first consider how density and centralization promote the emergence of distinctive governance practices that can be brought to bear on NPD projects within the cluster.

Cluster Density and NPD Project Governance. Cluster density refers to the relative number of ties in a network that links cluster members. It is the ratio of the number of relationships that exist in a cluster network to the total number of possible ties if each cluster member was connected to every other member (Rowley 1997). The effects of cluster density on governance choices within NPD projects can be understood broadly in terms of an access logic (Gnyawali and Madhavan 2001), in that access to other actors in dense clusters is facilitated by the multiple paths connecting cluster members. An example of a well-known high-density cluster is Silicon Alley in Manhattan, New York (Neff 2005). The area incorporates the Flatiron district and neighboring Chelsea, Tribeca, and Soho and is home to a high concentration of interrelated Internet and new media companies. It is third only to Silicon Valley and Route 128 in Boston in terms of venture capital investment.

We expect cluster density to promote relational governance practices among cluster members. This is because dense clusters support the emergence of shared relationship norms among constituent firms, which is a defining feature of relational governance (Macneil 1981).

\footnotetext{
${ }^{2}$ This perspective, grounded in Wasserman and Galaskiewicz's (1994) and Kilduff and Tsai's (2003) work on social network theory, comprises a set of metrics which help map the relationships inherent to regional clusters. To date, however, network research has mostly been applied to clusters using an 'egocentric' perspective in which the focal unit of analysis is the individual organization (e.g., Casper 2007; Owen-Smith and Powell 2004). Egocentric cluster research is clear on the influence of a particular firm's location within a cluster, however unlike a whole-of-network perspective, it does not shed light upon the properties of the cluster as a whole.
} 
Specifically, dense clusters facilitate access to other cluster members, which promotes norm formation through socialization and information accessibility. First, firms in a dense cluster more readily converge upon frames of reference, values, and attitudes through being exposed directly to, and learning from, the behaviors of other organizations within the cluster. Gençtürk and Aulakh (2007), for example, demonstrate that firms build relational governance more effectively when socialization within a group is stronger. Second, the local reputation systems that characterize dense clusters lead to faster convergence upon shared norms: News of uncooperative behavior spreads especially quickly in these contexts (Argote et al. 2003), which helps to establish the informal "rules of the game" (North 1987) that underpin relational governance.

As a specific example, Piore and Sabel (1984) describe how clusters exhibit the relational norm of flexibility. Once such broad norms have been established, they can be brought to bear on a given NPD project's relationships and decisions. For instance, a norm of flexibility may govern upstream design decisions (e.g., between suppliers and a manufacturers), as well as downstream pricing decisions (e.g., between manufacturers and resellers). In the case of Silicon Alley, described above, such flexibility is considered to be a key element of the informal system of governance that underpins inter-firm cooperation and relationship building in that cluster (Asheim and Gertler 2005), and a core component of its success. We therefore propose:

Proposition 1: The greater the density of the overall cluster, the higher the likelihood that relational governance practices can be brought to bear on a given NPD project.

Consider next how relational governance practices, once established, impact a project's performance outcomes. We expect the informal norms that characterize relational governance to help promote truly novel products (Dewar and Dutton 1986; Fang 2011). This is because of the 
ability of relational governance to support three innovation-related processes, namely 1) information transfer, 2) information use, and 3) adaptation to changing circumstances.

First, innovation at its core follows from novel combinations of tacit knowledge and competence (Fang 2011; Sivadas and Dwyer 2000; Sobrero and Roberts 2001; Von Hippel 1994; Wang et al. 2008). Extant social science research (e.g., Lawson and Lorenz 1999; Obstfeld 2005; Uzzi 1997) suggests that a relational governance structure, due to its particular communication codes and heuristics, is in a unique position to support the transfer of "thick" information between parties. Extant research in marketing (Dahlstrom et al. 1995; Olson et al. 1995) specifically shows that "organic" interfaces (Burns and Stalker 1961) facilitate information transmission that supports innovation.

Second, because relational norms align parties' goals, they promote the use of novel information. Terwiesch, Loch, and DeMeyer (2002, p. 402) note that while product development projects often "start in the dark" with unproven information which may be difficult and risky to apply, a supporting social structure gives parties the confidence to act on it, and without the need for extensive documentation (Uzzi 1997). For instance, Yalumba, an Australian winemaker in the Clare Valley in the South Australian wine cluster pioneered the use of the Stelvin ${ }^{\circledR}$ (screwcap) wine bottle closure - a truly novel product at the time. The development and subsequent widespread adoption of the screwcap closure was greatly aided by the pre-existing relational practices among the members of the cluster (Atkin et al. 2006).

Third, relational norms facilitate adaptation to changing circumstances. Over the course of an NPD project, multiple adjustments may be made to a product's technical architecture. In turn, downstream marketing decisions may need to be modified. Importantly, however, such adaptations are not automatic, because they impose costs on the firms in question (Buvik and 
John 2000). However, the "unitary actor" heuristic (Macneil 1981) that underlies relational governance specifically encourages parties to pursue value-enhancing activities. Ghosh and John (2005) note how inter-firm contracts for truly new products are necessarily incomplete, which places a premium on flexible interfaces which permit parties to "seek, provide, and accept assistance" (Sosa 2014). Hence, activities that contribute to product novelty, even costly ones, will be initiated and implemented. ${ }^{3}$

In the interest of balance, we identify a fourth sub-process, namely information search, which may actually be constrained by relational governance. Granovetter's (1973) tie strength thesis suggests that reliance on strong ties may limit the access to new information in the first place and thus impede search. Moreover, strong ties may also be associated with a lack of novel knowledge because they hinder firms' ability to 1) look for and identify knowledge and 2) move and incorporate knowledge across organizational boundaries. Hansen (1999) terms this dual challenge as the "search-transfer problem". Nonetheless, the combined positive effect of the other three processes discussed above (i.e., information transfer, information use, and adaptation) suggests that relational governance is associated with product novelty.

Thus, as a baseline expectation we suggest that relational governance practices that emerge in dense clusters will promote product novelty.

Cluster Centralization and NPD Project Governance. Centralized clusters are those in which one or a few parties - often referred to as 'hubs' - have a disproportionately large number of connections to other members within the cluster. Highly centralized clusters are often

\footnotetext{
${ }^{3}$ We note that complex information processing and adaptation needs are defining characteristics of so-called "radical innovation" projects (Henderson and Clark 1990). Most likely, such projects will benefit the most from relational governance practices. By comparison, incremental innovations like line extensions can be managed in mechanistic fashions, on the basis of pre-existing plans and standard operating procedures. The inherent inflexibility of the latter types of practices, however, will represent a constraint for truly novel products where the key interfaces and marketing requirements are ill-defined a priori (Argote et al. 2003; Damanpour 1991; Sosa et al. 2004).
} 
organized in a manner approximating a hub-and-spoke pattern (Provan et al. 2007). The central location of the hub organizations affords them greater influence over which interactions take place within the cluster and how they are governed (Arikan and Schilling 2011). The effects of cluster centralization can be understood in terms of a control logic.

In highly centralized clusters, hub firms assume a lead role in building common purpose and lending legitimacy to other members with which they are associated (Dhanaraj and Parkhe 2006). A well-known example of a highly centralized cluster is the "Square Mile" financial services cluster in London, UK. This financial cluster is located in downtown London and the smaller Canary Warf region two and a half miles to the east. The industry is particularly concentrated with the largest four banks (Barclays, HSBC, Lloyds, Royal Bank of Scotland) accounting for $85 \%$ of the business current account market (Independent Commission on Banking 2011).

We expect cluster centralization to promote hierarchical governance practices in a given cluster, for the following reasons. First, hub firms can use the power and information advantages that stem from their central network position to establish formal contracts and agreements in a given project, and unilaterally impose them on their partners [e.g., General Motors in its recent top down reorganization of its supply chain (Lassa 2014)]. Second, in light of these asymmetries hub firms in centralized clusters are further motivated to adopt hierarchical governance because it helps them to overcome decision obstacles and achieve efficient convergence through the careful specification of decision rights at each stage of the NPD process, from the early product idea through to commercialization (Wheelwright and Clark 1992). Third, hub firms that occupy central positions within clusters have, by definition, a greater than average number of connections with other member firms. This increases the likelihood that peripheral firms will 
have been exposed to hierarchical governance practices (Argyres and Mayer 2007), which in turn makes it more likely that these firms will deploy such practices in their relationships with other less central cluster members. In other words, the actions and reach of hub firms support the normalization of hierarchical project governance across centralized clusters.

For instance, in the London Square Mile example outlined above, centralization promotes control on the part of the cluster's large banks. This facilitates a hierarchical system of governance both because it helps these hub firms enforce formal rules and because it has become the 'standard' way of organizing relationships in this cluster (Cook et al. 2007). Taken together, our arguments suggest that cluster centralization promotes hierarchical governance practices. We therefore propose that:

Proposition 2: The greater the centralization of the overall cluster, the higher the likelihood that hierarchical governance practices can be brought to bear on a given NPD project.

Consider next the likely project-level performance implications of hierarchical governance. We expect this form of governance to promote speed to market (Fang 2011; Rindfleisch and Moorman 2001), due to the availability of standardized rules and conflict resolution mechanisms.

First, under hierarchical governance, the relevant relationships and interfaces are managed in a mechanistic "planning" mode (Burns and Stalker 1961; Thompson 1967), which allows for the setup of rules of engagement and standard operating procedures (Dahlstrom et al. 1995; Stinchcombe 1986). Wheelwright and Clark (1992) illustrate such a governance mode in a new product development context through a so-called "project book" which specifies in advance the key requirements and procedures for a given project. 
Second, because hierarchical governance provides specific blueprints for action (Eisenhardt and Tabrizi 1995), it creates efficiency by “preventing deviation” (Ulset 1996) and overcoming potential integration barriers in advance (Griffin and Hauser 1996; Sobrero and Roberts 2001). Any conflict that emerges between partners can be resolved according to a set of pre-determined protocols (Bstieler and Hemmert 2010; Gulati and Singh 1998) which translate into quick decision-making and ultimately speed to market for a given new product. ${ }^{4}$

Volkswagen, for example, has sought to distinguish itself from other car manufacturers through a strong focus on environmental sustainability. As a result, VW requires all suppliers to adhere to a particular set of principles as they develop new components for a particular model. Suppliers deemed to fall short may be cut from the supply chain, "meaning that a supplier that does not fulfil required environmental and social standards will not be awarded a [future] sourcing contract" (Koplin et al. 2007, p. 1059).When Volkswagen opens a new production facility anywhere in the world, its first tier suppliers are contractually required to establish operations in a proximate location. This allows VW to build an extensive local supplier network quickly and efficiently that mimics its German operations, thereby facilitating the faster launch of existing products in new markets (Depner and Bathelt 2005).

Thus, as a second baseline expectation we suggest that the hierarchical governance practices that emerge in centralized clusters will promote speed to market. ${ }^{5}$

\footnotetext{
${ }^{4}$ This begs the question of whether our other form of governance (i.e., relational) affects speed. We expect that aspects of relational governance, such as the limited need to qualify and monitor partners, may produce time economies. Moreover, trust and rich communication linkages can facilitate coordination (Dyer and Singh 1998; Rowley et al. 2000). At the same time, the complex adaptation processes that characterize relational exchange (Eppinger 2001; Fang 2008) may have the opposite effect and actually undermine speed to market.

${ }^{5}$ While hierarchical governance is inherently associated with speed, its mechanistic quality may only be suitable for familiar projects, where the causal ambiguity would not strain the focal rules (Adler 1995; Gerwin 2004; Venkataraman 1997). Specifically, hierarchical governance may only be appropriate for incremental innovations, where the product architecture and marketing requirements are well-understood a priori (Cohen et al. 1996; Sosa et al. 2004). Sivadas and Dwyer (2000) illustrate this point by arguing that a standard "Stage-Gate" process may not lend itself to radical innovations. For radical innovations, the likelihood of encountering exceptions during the process undermines the utility of fixed rules and plans.
} 


\section{The Moderating Effects of Cluster Configuration}

Propositions 1 and 2 above express how different aspects of cluster configuration density and centralization - support the emergence of particular governance practices (relational, hierarchical) in the first place. These practices, in turn, are associated with particular new product outcomes. Next, we consider how cluster configuration may also play a second role; namely to enhance the effects of relational and hierarchical governance on their respective performance outcomes. Our core argument is that network density and centralization enhance clustered firms' ability to fully exploit the two forms of governance.

Consider again our expectation that relational governance will promote product novelty due to its ability to transfer tacit knowledge, support the use of new information, and help parties adapt to changing circumstances. We posit that cluster density augments the ability of clustered firms to capitalize upon the properties of relational governance ex post, and thus ensure that such governance practices, when used for a given project, do indeed deliver novel products, for the following reasons ${ }^{6}$.

First, because partners have the opportunity to interact more directly and frequently in dense clusters, density supports relational governance's capability for information transmission and use. Ultimately, this increases the likelihood of the serendipitous discovery of new insights. For example, fully one-third of the approximately forty winemakers in the Clare Valley region in the South Australian wine cluster were, due to their dense connections, mobilized to sign off on,

\footnotetext{
${ }^{6}$ We note a possible counterargument, which is that cluster density may impede the ability of clustered firms to capitalize upon the properties of relational governance. This is because density has been associated with redundancy (Burt 1992). Specifically, it has been argued (e.g., McFadyen et al. 2009; Rodan and Galunic 2004) that while density facilitates knowledge transfer it may also increase knowledge redundancy, which can constrain the novelty of knowledge that can be accessed. In other words, while density leads to increased opportunities for combining new knowledge, these opportunities may be offset by "combinatorial exhaustion" (Mahmood et al. 2013, p. 1526). While acknowledging this possibility, we align our arguments with Gnyawali and Madhavan (2001) who posit that firms in dense networks can take steps to mitigate redundancy problems by purposively structuring their own networks in order to eliminate redundant ties.
} 
and take part in, the "Riesling with a twist" campaign. It was the dense pattern of winemakers in this small sub-region that promoted the sharing and deployment of information in the cluster, and made this collaborative initiative possible (Choi et al. 2010).

Second, the opportunity for face-to-face interaction that is facilitated by cluster density allows regular informal monitoring of projects which, in turn, enables early identification of, and timely adjustments to, changing circumstances. For example, frequent and evolving collaborations between winemakers in the South Australian wine cluster and researchers at Roseworthy College (a University focusing on oenology research and located within the region) allowed partners in the Clare Valley identify and pursue ongoing refinements to the Stelvin closure technology (Taber 2009). Thus, network density helps promote product novelty due to its ability to support relational governance practices in a cluster over time. We therefore propose the following:

Proposition 3: The effect of relational governance practices in an NPD project on product novelty will be enhanced by cluster density.

Consider next the baseline expectation that the hierarchical governance of a cluster transaction will promote speed to market for a given product due to this governance form's emphasis on rules and standard operating procedures and its transparent approach to conflict resolution. Here we posit that cluster centralization enhances the ability of clustered firms to exploit the benefits of hierarchical governance ex post. This is because network centralization supports the inherent coordination properties of hierarchical governance by enhancing firms' ability to enforce formal governance practices. Specifically, communication flows in centralized clusters are likely to be clearer and more predictable as they are more likely to be mediated by a few dominant hub firms. The resulting clarity is likely to facilitate closer adherence to standards. For example, the location of VW's flagship Autostadt car dealership in Wolfsburg, which is 
close to its main production location and network of suppliers, facilitates rapid flows of information across the entire value chain (Kooijman and Sierksma 2007).

When conflict does emerge, the enforcement of formal contracts is also less costly in centralized clusters because the actions of hub firms are more visible, which means that the invocation of explicit rules requires less effort. Where a hub firm sanctions a supplier, both the sanction and its effects will be more apparent in centralized clusters than in dense clusters because of the profile enjoyed by hub firms. This means that the reputational risks are higher for firms in centralized clusters and, therefore, the incentive to reach a speedy resolution will be greater. Volkswagen, for example, pioneered a local modular system of production in Brazil in which suppliers are responsible for whole subsystems of a given vehicle, with VW responsible for final assembly of the subsystems (Van Hoek and Weken 1998). Suppliers are co-located on the same site, with bridges physically connecting the suppliers to the main production facility. This centralized cluster structure allows VW to exert authority through "spatial and organizational contiguity" (Frigant and Lung 2002, p. 752), which induces supplier compliance. Ultimately, then, network centralization promotes speed to market, because it supports, on an ongoing basis, the ability of hierarchical governance to reduce friction between decision-makers. This line of argument leads to our fourth proposition:

Proposition 4: The effect of hierarchical governance practices in an NPD project on speed to market will be enhanced by cluster centralization.

\section{Mismatch Scenarios}

Our preceding discussion has two key implications. First, the unique configuration of a cluster represents a particular source of governance practices in the first place. Second, to the extent that a given NPD project involves members of the same cluster, the firms in question subscribe to common governance practices. Conceptually, one may think of NPD activity in a 
cluster context in terms of a particular temporary sub-network of firms that is defined by the project in question. The shared governance practices that characterize the interactions within the sub-network have unique performance implications (specifically, in terms of novelty and speed), due to particular matches between structure (configuration) and process (governance).

From a theoretical standpoint, these propositions express Granovetter's (1999) conjecture that micro-level governance practices cannot be studied in isolation, and that "context and action" interact (p. 192). Parallel arguments underlie emerging multi-level models of governance in transaction cost theory (e.g., Williamson 2000), although testable propositions regarding specific matches and their implications have been lacking. Our propositions build on earlier work (Antia and Frazier 2001; Wuyts and Geyskens 2005) to address this deficiency.

The notion of matches between configuration and governance logically raises a follow-up question about mismatches and their effects. Conceivably, mismatches may be benign, to the extent that performance outcomes simply fail to materialize given a lack of fit between cluster configuration and project governance. It is possible, however, that mismatches may have more dramatic effects, and actually impede performance by producing coordination "gaps" at key points of a product development process (Gerwin 2004; Heath and Staudenmayer 2000) and giving rise to incremental transaction costs.

In the sections below, we examine two different types of mismatches. The first pertains to misalignment between the governance of a particular project and the cluster's overall configuration. The second type is mismatches from using different (and potentially incompatible) governance mechanisms in different relationships within a given project.

Governance vs. Configuration Mismatches. Consider again P3 and the interaction between relational governance and cluster density on product novelty. Our rationale for this 
prediction hinged on the ability of a dense cluster to support relational norms' capacity to promote novel product outcomes. More specifically, we expected dense clusters to facilitate the ongoing transfer of tacit information, support the use of new information, and improve partners' ability to adapt to changing circumstances, thereby increasing the potential for product novelty.

In contrast, consider how relational governance may function within a centralized cluster, where hub firms represent dominant authority structures. Such a scenario may happen because of changing cluster dynamics, or due to firm entry or exit. For example, as a dense cluster matures, a number of dominant hub firms may emerge or a new dominant firm may relocate from elsewhere. Because relational norms developed over time are "sticky" (Li et al. 2010) they may remain in place, at least for some time, but the resource advantages of the hub firms means that the cluster's overall configuration changes from density to centralization ${ }^{7}$. For example, the technology cluster in Cambridge (England) - "Silicon Fen" - was originally characterized by a dense pattern of firms in the software and electronics industries. As the cluster has developed, however, it has become increasingly dominated by a small number of hub firms, of which semiconductor design company ARM is the most important. This has changed the structure of the cluster to a relatively centralized one, although the relational norms that characterized its formative years have broadly remained in place (Garnsey and Heffernan 2005).

The above scenario represents a mismatch that hinders the ability of relational governance to generate novel products. First, the normal capacity to process tacit information will be constrained by the relative lack of ties in a centralized cluster, which impedes informal communication. This is because firms are less likely to have the opportunity to develop the

\footnotetext{
${ }^{7}$ Note that while networks may possess a degree of both density and centralization, they cannot be simultaneously maximized (Morrissey et al. 1994). A key theoretical assumption underlying our framework is that density and centralization do not constitute endpoints on a single continuum.
} 
particular relationship building skills required for relational governance. Equally important, centralization weakens a cluster's on-going socialization processes, and thus the ability of firms to coordinate as "unitary actors". In fact, the threat of unilateral enforcement by a central hub firm has the potential to "crowd out" the bilateral norms that underpin relational governance (Deci et al. 1999; Osterloh and Frey 2000) and therefore any experimental or creative ways in which partners might use and combine new information. Finally, centralized clusters inhibit informal monitoring, which relies on frequent communication by multiple parties, thereby increasing the potential for inertia around dominant firms' rules and thus reducing partner firms' ability to adapt to changing circumstances. In a centralized cluster, then, using relational norms to promote novelty may be ineffective. In proposition form:

Proposition 5: The effect of relational governance practices in an NPD project on product novelty will weaken at higher levels of cluster centralization.

Next, consider P4 that focused on the interaction between hierarchical governance and cluster centralization on speed to market. The logic of the match scenario underlying P4 was based on a centralized cluster's ability to facilitate conformance to rules and standard operating procedures through clear lines of authority and communication, and the efficient resolution of conflict, thus reducing friction and promoting speed to market. Theoretically, the combination of formal rules and enforcement by centralized authority reflects an internally consistent Weberian (1947) "ideal type" of governance system.

In contrast, consider how hierarchical governance is likely to function within a dense cluster. As an example, this may happen when intellectual property concerns are acute. Thus firms in a dense cluster may be involved in developing products for a commercially very sensitive new technology. This may require cluster members to adhere to hierarchical governance practices even though the overall configuration does not support such practices. 
Silicon Valley, for instance, remains one of the largest recipients of defense contracts in the United States (Leslie 2000), almost all of which are governed in a hierarchical manner despite the dense structure of the Silicon Valley cluster.

The above scenario represents a mismatch, because the formal governance rules in question lack obvious channels of authority and thus recourse to strong guidelines and remedies should they be required. Indeed, the use of fixed rules in such a situation, in which frequent and informal interactions normally underpin relationship norms, may be viewed as illegitimate. In addition to increasing markedly the costs of invoking formal rules, this may render them largely ineffective in facilitating on-going decision-making. For example, analysis of the use of formal contracting in Silicon Valley has found that it "elevate[s] transaction costs, imperil[s] economic activity, and foster[s] interorganizational discord" (Suchman and Cahill 1996, p. 679). In these circumstances, the reputational risk for parties that seek to enforce hierarchical governance practices when conflict arises may be greater than for parties that are deemed to have broken the rules. In a dense cluster, then, using fixed rules and unilateral enforcement of conflict resolution with the goal of promoting speed is likely to cause discord, which is counterproductive from a time to market standpoint. We therefore propose the following:

Proposition 6: The effect of hierarchical governance practices in an NPD project on speed to market will weaken at higher levels of cluster density. ${ }^{8}$

Intra-project Mismatches. Propositions 5 and 6 above expressed the effects of mismatches between a cluster's larger configuration and the mechanisms used to govern the relationships between the individual parties to the project. In developing these mismatch

\footnotetext{
${ }^{8} \mathrm{We}$ focus on mismatches that impede governance mechanisms' value-creation effect. We note that past research has reported interactions between structure and process that would appear to constitute mismatches in our framework, but which actually have efficient outcomes. For instance, Wuyts and Geyskens (2005) show that the combination of tight contracts and network embeddedness suppresses opportunism. This is an important finding, but its key contribution is to show how a certain combination of structure and process mitigates negative outcomes (rather than promoting positive ones).
} 
scenarios, we assumed that the different relationship-level governance mechanisms themselves were compatible with each other, given the parties' common cluster membership which provides access to similar governance practices.

We now consider an alternative type of mismatch; one that follows from the use of different governance mechanisms (relational vs. hierarchical) across relationships within a particular NPD project. Past research has suggested that different governance mechanisms may indeed be incompatible with each other (Heide et al. 2007; Kumar et al. 2011), but the implications for new product development have not been explored.

As a specific example, assume that a particular NPD project, which comprises a set of incumbent cluster firms (e.g., supplier, product designer, manufacturer) that share pre-existing relational governance practices, requires a sub-assembly component from a new supplier that is located outside of the cluster. The new supplier is not only unfamiliar with the cluster's relational practices; it may be approaching the project with a distinctly hierarchical mindset originating, perhaps, from transactions within a different cluster.

Such a situation represents a particular form of mismatch. The existing relational governance practices between the incumbent firms have the potential, as per our earlier discussion, to promote product novelty. For instance, the transfer of tacit information is facilitated by a "thick" organizational interface. This prerequisite is lacking, however, if the new supplier subscribes to different governance practices. If this supplier does not share the preexisting relational norms, information transfer and use at critical stages of the NPD process will be impeded. In addition, without common norms key adaptations at vital project junctures may not take place. Ultimately, then, the opportunity to bring a novel product to market will be compromised. In proposition form: 
Proposition 7: The effect of relational governance practices in an NPD project on product novelty will weaken given hierarchical governance practices in connected project relationships.

Finally, consider a mismatch scenario where the incumbent firms in a cluster (e.g., upstream suppliers, designers, manufacturer) share hierarchical governance practices, but are working with a reseller in a particular market outside the cluster whose pre-existing governance mode is relational in nature. Here, the downstream reseller will have difficulty abiding by the incumbent firms' fixed rules and monitoring practices. As a consequence, the usual ability of hierarchical governance to promote speed to market, as per our earlier discussion, will be compromised. Again, a governance mismatch produces friction which undermines performance. We summarize the preceding discussion with the following proposition:

Proposition 8: The ability of hierarchical governance practices in an NPD project on speed to market will weaken given relational governance practices in connected project relationships.

\section{Discussion}

In this final section we begin by explaining how our conceptual framework informs three different bodies of research, namely new product development, inter-firm governance, and regional clusters, respectively. Next, we sketch out some key implications for marketing practice and decision-making. We close with a discussion of topics for future research.

\section{Theoretical Implications}

Implications for New Product Research. In a comprehensive review of the new product development literature, Hauser et al. (2006) pointed to the different academic fields which have studied innovation. At the same time, they also noted a striking lack of linkages between these streams of work. One of our current aims was to develop such linkages by bringing together extant work on NPD, regional clusters, and inter-firm governance. In general, our framework 
provides a macro-level perspective on new product development; a perspective that remains relatively underutilized in marketing (Tellis 2013).

Increasingly, firms' new product initiatives involve external parties such as suppliers and resellers (Rindfleisch and Moorman 2001). This, in turn, suggests that firms' NPD strategies must account for inter-firm governance issues. Our framework shows that a cluster, by virtue of its particular configuration, is a source of governance practices in the first place. This has potentially important implications. To the extent that the interactions between the different upand downstream members of a NPD process are guided by cluster-wide governance practices, it reduces friction which can otherwise compromise new product outcomes. As such, if clustering helps to generate joint governance ground rules among firms, it represents a considerable source of efficiency.

Implications for Research on Inter-firm Governance. Our framework has implications for the literature on inter-firm governance, in particular for its transaction cost branch. We highlight four particular ones. First, we build on prior work (e.g., Ghosh and John 1999; Ghosh and John 2005) which suggests that firms' governance choices have value-creating effects that go beyond suppressing opportunism per se.

Second, while the focus of past governance research has often been on the micro-level mechanisms themselves, we add to a relatively small literature in marketing (e.g., Antia and Frazier 2001; Wuyts and Geyskens 2005) which shows that the context in which governance mechanisms are deployed matters. In our framework, we capture context through the cluster configuration construct, and posit that new product outcomes follow from appropriate matches between governance mechanisms and cluster configuration. Importantly, we highlight the dual 
role of configuration as 1) an ex ante driver of governance practices and 2) an ex post facilitator of performance.

Third, we have identified cluster density as a specific source of relational governance. In extant transaction cost theory the governance mechanisms themselves are typically treated as exogenous, which has raised questions about how certain governance practices actually come about. In particular, researchers (e.g., Ghosh and John 2012) have questioned how relational mechanisms emerge in the first place. Given the importance of relational governance, as evidenced by the sizeable literature that has emerged since Macaulay's (1963) seminal paper, this is an important question, and our cluster-based reasoning sheds light on the issue.

Finally, our explicit consideration of how governance practices come about points to possible constraints on transaction cost theory's "discriminating alignment" principle (Williamson 2010). At its core, transaction cost theory remains a normative framework, whose distinct strength is the articulation of a firm's motivation to deploy particular governance mechanisms. The theory is less explicit, however, about a firm's ability to do so. Our framework suggests that ability resides in the particular nature of the context (a cluster in this instance) in which a firm is embedded. This also suggests, however, that constraints may exist on firms' governance choices, and that firms may face limited governance "menus" by virtue of their geographic location. For instance, relational mechanisms may not be readily available in centralized clusters. In general, our present arguments point to the need for joint considerations of motivation and ability in making governance decisions.

Implications for Cluster Research. Research on clusters across the social sciences, both in geography (e.g., Asheim and Isaksen 2002; Keeble and Wilkinson 1999) and economics (e.g., Kaldor 1972; Krugman 1991; McCann and Sheppard 2003) has generally considered 
performance at the aggregate level of the cluster. As noted, however, while there exists evidence of successful clusters, there are also many documented instances of unsuccessful ones. This suggests a need for more fine-grained theoretical explanations of performance that go beyond clustering per se. We believe our framework represents an initial step towards providing such an explanation. Specifically, we take a "bottom up" or disaggregated perspective, based on the assumption that understanding cluster performance requires, as a starting point, explicit attention to how individual cluster projects are governed. The larger cluster configuration matters, but in our framework its primary roles are to help set up governance practices and then to facilitate their impact on NPD performance.

\section{Managerial Implications}

While detailed managerial prescriptions must await empirical testing, we offer two suggestions for marketing decision-making, pertaining to 1) the role of firm location, and 2) the management of the new product conversion process.

The Role of Location. Our discussion of cluster configuration suggests that a firm's geographical location may support as well as constrain its new product decisions. As a consequence, a firm's new product objectives must be considered against the backdrop of its location options. For instance, firms for which product novelty is paramount should favor dense clusters due to their relational governance practices which inherently support such outcomes. As a specific example, in 1999 financial services firm J.P. Morgan took a strategic decision to locate its European Technology Center - a division charged with developing novel and complex financial software and technology systems to support J.P. Morgan's global operations - in Glasgow, Scotland. Glasgow is known for its dense connections among firms, and for its focus on high-value R\&D and product development in the ICT industry, a fact that has earned the region the moniker "Silicon Glen" (Aziz et al. 2011). In a parallel fashion, firms for which speed 
to market is paramount should favor centralized clusters due to their hierarchical governance practices which inherently support such outcomes. For example, the shoe cluster in Sinos Valley, Southern Brazil, has seen rapid growth in the presence of international footwear manufacturers, particularly from the US, which are attracted in part by its hierarchical nature, which allowed firms to produce large volumes of standardized products which could be brought to market quickly (Humphrey and Schmitz 2002).

Our framework also suggests that location may come to represent an external constraint (c.f., Pfeffer and Salancik 1978), and require a firm to consider strategic realignment (or, possibly, relocation, depending on the relative level of reversibility of both its location and strategy decisions). For example, firms whose strategies involve product novelty may experience challenges in centralized clusters, and they may benefit from changes to their strategy. Such a dynamic is evident in the whisky cluster in Scotland where firms have altered radically their strategy in recent decades in response to changing market conditions. Specifically, as supermarkets have asserted their buying power and Scotch whisky has been subject to greater international competition, they have placed much greater emphasis on efficiency and speed to market. This has seen the whisky cluster evolve from a "cottage industry" comprising many producers and a fragmented supply chain of malters, cooperages (barrel makers), bottling plants, and distributors, to a consolidated structure in which three multinational companies (Diageo, Allied-Domecq and Seagrams) are responsible for $80 \%$ of production. These firms have reshaped the supply chain from one characterized by informal relationships between artisans to one characterized by "centralized decision making" (Whittam and Danson 2001, p. 960) on the part of dominant players. As a result, smaller producers with a traditional focus on product differentiation have been required to make strategic changes including "significant investment in 
just-in-time techniques" and the development of "larger and more efficient bottling plants and distilleries" (Whittam and Danson 2001, p. 957) in order to adapt to the increasingly centralized nature of the cluster.

Alternatively, firms whose strategies involve speed to market may be constrained by cluster density. Ultimately, such constraints could require firms to make costly trade-offs between strategy realignment and relocation. The Pittsburgh steel industry is an example of a cluster that has transitioned from a highly centralized structure, one dominated by a handful of very large steel mills, to a fragmented structure of smaller mini-mills and ancillary firms focused on design, engineering, drafting, welding and machining services, following the collapse of the high volume steel manufacture in the 1980s. With the largest firms in decline and heading towards bankruptcy, the small firms that remained survived by changing their strategy away from the mass manufacture or processing of steel to the provision of specialized services that rely on innovation. In doing so, these firms have engaged in high levels of collaboration including "joint-bidding for contracts and co-operating in provision of complementary services" (Cooke 1996, p. 165).

Managing the New Product Conversion Process. The particular constructs that our framework comprises are likely to play crucial roles in shaping a new product's conversion (Chandy et al. 2006; Ulrich and Eppinger 2011), namely from an initial idea to a concept, and from concept to marketed product. Interestingly, the cluster literature has historically limited its focus to the initial idea generation stage of a new product development process, based on the expectation that co-located firms benefit from knowledge spillovers. Our framework suggests that the benefits of clustering extend beyond idea generation per se, by virtue of aligning key 
interfaces between the relevant upstream (e.g., suppliers) and downstream (e.g., resellers) parties that comprise an NPD process.

Achrol and Kotler (1999) note the "traditional marketing struggle" involved in achieving integration between $\mathrm{R} \& \mathrm{D}$, design, and consumer research. While managing just one of these interfaces represents a considerable challenge, favorable new product outcomes ultimately depend on how the entire set of inter-firm relationships are governed. To the extent that the relevant participants in a given NPD project subscribe to common governance practices, it goes a long way to overcoming possible obstacles. Specifically, the ability to bring joint governance practices to bear on a particular cluster project increases the likelihood that both 1) an initial idea will be successfully converted into an appropriate concept, and 2) the concept will subsequently be converted into a full-fledged marketed product.

For example, the development by General Motors of the Chevrolet Volt - one of the first mass manufactured plug-in hybrid electric vehicles - was facilitated by the emergence of a series of firms and research institutes within the Detroit automotive cluster specializing in different aspects of electric vehicle design and production such as capacitors, electronics for thermal management, and fuel cells (Lyon and Baruffi 2011). GM was able to take advantage of the centralized structure of the Detroit automotive cluster, its status as a hub firm within it, and its existing distribution network in order to successfully convert the initial product idea into a marketed product in a remarkably short time.

\section{Directions for Future Research}

Our framework suggests specific opportunities for future research. First, an obvious starting point would be to test the model empirically. As with any empirical studies of clusters, researchers would face a number of core challenges, including the delineation of cluster boundaries and the determination of cluster membership (Feser and Bergman 2000; O’Donoghue 
and Gleave 2004). Moreover, there are challenges in measuring project performance, although marketers have developed robust measures of both the dependent variables in our framework speed to market and product novelty (Rindfleisch and Moorman 2001) - which have been operationalized effectively in a cluster context (Ganesan et al. 2005).

Second, there may be more complex constellations of variables that influence particular governance choices, such as national culture, which are not included in our model. For example, Japanese manufacturers like Toyota are known for their use of relational governance practices in supplier relationships (Sako 2004), yet the clusters in which these firms operate are highly centralized. This seems to contradict our model, which posits that centralized clusters will tend to exhibit cluster-wide hierarchical governance practices. One plausible explanation for this apparent inconsistency is that Japan's national culture provides a set of informal constraints "that serve to economize on the transaction costs of achieving cooperation" (Hill 1995, p. 121), which is not available to firms in the West [see also Achrol (1997) and Dyer and Chu (2003)]. Thus future research could usefully consider the influence of culture and other national institutions on governance decisions within clusters.

Third, in order to highlight some basic relationships between cluster configuration, project-level governance, and new product outcomes we limited ourselves to stating basic linear relationships between the different variables. It is possible, however, that some of the relationships in question are more complex than that. For instance, some of the relationships may be associated with threshold effects of various kinds. As a specific example, strong relational norms may produce conditions of "over-embeddedness" (Granovetter 1985) and "groupthink" (Janis 1982) that undermine parties' efforts and ultimately new product outcomes (Argote et al. 2003; Ayers et al. 1997). At the very least, this suggests that relational governance may be 
subject to diminishing marginal returns (Wuyts and Geyskens 2005) with respect to novelty. Somewhat similarly, while we implicitly suggested that cluster density would have general governance benefits, there may exist a threshold beyond which the number of ties actually serves as a constraint on a firm's ability to communicate with partners face-to-face.

Fourth, a key feature of clusters is the geographic proximity of the firms in question (Bathelt et al. 2004). However, the distances spanning cluster members can vary significantly between clusters (Martin and Sunley 2003). While Ganesan et al.'s (2005) research raised questions about the role of proximity per se in new product development, it is conceivable that proximity may serve certain moderating purposes within our framework. For instance, the effect of cluster density on relational governance may be enhanced by the relevant parties' proximity, since it promotes the establishment of interaction rules and thus facilitates inter-firm socialization processes (Morgan 2004). Further, proximity may strengthen the effect of centralization on hierarchical governance, since it facilitates the negotiation of unilateral contracts (Gilson et al. 2009). Another possibility is that proximity may actually have deleterious effects on product outcomes in some circumstances. For example, proximity can promote the development of cliques, which may undermine the effectiveness of relational governance (Gnyawali and Madhavan 2001). As a specific example, Giuliani's (2007) study of three wine clusters in Chile and Italy shows that "in spite of the presence of pervasive business interactions" within these relational clusters, the existence of cliques means that "innovation-related knowledge is exchanged in a rather uneven and selective way" (p. 163), which undermines innovation. Thus, proximity may play an indirect role through its interactions with other variables. 
Finally, interesting research questions also pertain to the content of the relationships between cluster members. Our current focus was on these relationships' economic dimension, as reflected in their governance mechanisms. However, cluster relationships are likely multiplex in nature, in that they comprise social as well as economic elements (Heide et al. 2007; Uzzi 1996; Wasserman and Faust 1994). As shown by Tuli, Bharadwaj, and Kohli (2010), multiplexity is associated with benefits, such as access to private information. For instance, the Cambridge technology cluster, for which the University of Cambridge represents a key institution, benefits from a unique communication channel, namely the University's college structure (Dacin et al. 2010).

We note, however, that the social dimension of cluster relationships may impose costs as well as benefits. As such, multiplexity may have complex effects: Dahl and Sorenson (2012) suggest a "regional embeddedness" thesis, which describes how entrepreneurs' preferences for a home region may influence their location choices above and beyond financial considerations. From this perspective, a decision maker's preference for spending time with friends and family may serve as a distraction and cause acceptance of lower financial rewards. In general, this reinforces the view that theorizing about more complex models of clusters is warranted. We hope that our framework will stimulate additional interest from marketers in this important area of inquiry. 


\section{References}

Achrol, Ravi S (1997), "Changes in the theory of interorganizational relations in marketing: Toward a network paradigm," Journal of the Academy of Marketing Science, 25 (1), 56-71.

Achrol, Ravi S and Philip Kotler (1999), "Marketing in the Network Economy," Journal of Marketing, 63 (4), 146-63.

Adler, Paul S (1995), "Interdepartmental interdependence and coordination: The case of the design/manufacturing interface," Organization Science, 6 (2), 147-67.

Antia, Kersi D and Gary L Frazier (2001), "The severity of contract enforcement in interfirm channel relationships," Journal of Marketing, 65 (4), 67-81.

Argote, Linda, Bill McEvily, and Ray Reagans (2003), "Managing knowledge in organizations: An integrative framework and review of emerging themes," Management Science, 49 (4), 571-82.

Argyres, Nicholas and Kyle J Mayer (2007), "Contract design as a firm capability: An integration of learning and transaction cost perspectives," The Academy of Management Review, 32 (4), 1060-77.

Arikan, Andac T (2009), "Interfirm knowledge exchanges and the knowledge creation capability of clusters," The Academy of Management Review, 34 (4), 658-76.

Arikan, Andac T and Melissa A Schilling (2011), "Structure and governance in industrial districts: Implications for competitive advantage," Journal of Management Studies, 48 (4), 772 803.

Arrow, Kenneth J (1969), "The organization of economic activity: Issues pertinent to the choice of market versus nonmarket allocation," in The Analysis and Evaluation of Public Expenditure: The PPB System. Washington D.C.: Vol. 1 U.S.Joint Economic Committee, 91st Congress, 1st Session, U.S. Government Printing Office.

Asheim, Bjorn T, Philip Cooke, and Ron Martin (2013), Clusters and Regional Development: Critical Reflections and Explorations. Oxford: Routledge.

Asheim, Bjorn T and Meric S Gertler (2005), "The geography of innovation: Regional innovation Systems," in The Oxford Handbook of Innovation, Jan Fagerberg and David C Mowery and Richard R Nelson, eds. Oxford: Oxford University Press.

Asheim, Bjorn T and Arne Isaksen (2002), "Regional innovation systems: The integration of local 'sticky' and global 'ubiquitous' knowledge," The Journal of Technology Transfer, 27 (1), 77-86.

Atherton, Andrew and Andrew Johnston (2008), "Clusters formation from the "bottom-up": A process perspective," in Handbook of Research on Cluster Theory, Charlie Karlsson, ed. Cheltenham: Edward Elgar.

Atkin, Thomas S, Rosanna Garcia, and Larry S Lockshin (2006), "A multidimensional study of the diffusion of a discontinuous innovation." Boston, MA: Working Paper, Northeastern University Institute of Global Innovation Management.

Ayers, Doug, Robert Dahlstrom, and Steven J Skinner (1997), "An exploratory investigation of organizational antecedents to new product success," Journal of Marketing Research, 34 (1), 107-16.

Aziz, Kamarulzaman Ab, Stanley Richardson, and Azlina Ab Aziz (2011), "Universities as key actors for cluster development: A case study of the Glasgow-Edinburgh corridor," in International Conference on E-business, Management and Economics. Hong Kong: IACSIT Press. 
Bathelt, Harald, Anders Malmberg, and Peter Maskell (2004), "Clusters and knowledge: Local buzz, global pipelines and the process of knowledge creation," Progress in Human Geography, 28 (1), 31-56.

Baum, Joel AC, Andrew V Shipilov, and Tim J Rowley (2003), "Where do small worlds come from?," Industrial and Corporate Change, 12 (4), 697-725.

Beccatini, Giacomo (1989), "Sectors and/or districts: Some remarks on the conceptual foundation of industrial economics," in Small Firms and Industrial Districts in Italy, Edward J Goodman and Julia Bamford and Peter Saynor, eds. London: Routledge.

Bell, Simon J, Paul Tracey, and Jan B Heide (2009), "The organization of regional clusters," Academy of Management Review, 34 (4), 623-42.

Bradach, Jeffrey L and Robert G Eccles (1989), "Price, authority, and trust: From ideal types to plural forms," Annual Review of Sociology, 15 (1), 97-118.

Bristow, Gillian (2005), "Everyone's a 'winner': Problematising the discourse of regional competitiveness," Journal of Economic Geography, 5 (3), 285-304.

Bstieler, Ludwig and Martin Hemmert (2010), "Increasing learning and time efficiency in interorganizational new product development teams," Journal of Product Innovation Management, 27 (4), 485-99.

Burns, Tom E and George Macpherson Stalker (1961), The Management of Innovation. London: Tavistock.

Burt, Ronald S (1992), Structural Holes: The Social Structure of Competition. Boston, MA: Harvard University Press.

Buvik, Arnt and George John (2000), "When does vertical coordination improve industrial purchasing relationships?," Journal of Marketing, 64 (4), 52-64.

Casper, Steven (2007), "How do technology clusters emerge and become sustainable? Social network formation and inter-firm mobility within the San Diego biotechnology cluster," Research Policy, 36 (4), 438-55.

Chandy, Rajesh, Brigitte Hopstaken, Om Narasimhan, and Jaideep Prabhu (2006), "From invention to innovation: Conversion ability in product development," Journal of Marketing Research, 43 (3), 494-508.

Choi, Pilsik, Rosanna Garcia, and Colette Friedrich (2010), "The drivers for collective horizontal coopetition: A case study of screwcap initiatives in the international wine industry," International Journal of Strategic Business Alliances, 1 (3), 271-90.

Cohen, Morris A, Jehoshua Eliasberg, and Teck-Hua Ho (1996), "New product development: The performance and time-to-market tradeoff," Management Science, 42 (2), 17386.

Commons, John R (1931), "Institutional economics," The American Economic Review, 21 (4), 648-57.

Cook, Gary AS, Naresh R Pandit, Jonathan V Beaverstock, Peter J Taylor, and Kathy Pain (2007), "The role of location in knowledge creation and diffusion: Evidence of centripetal and centrifugal forces in the City of London financial services agglomeration," Environment and Planning A, 39 (6), 1325-45.

Cooke, Philip (1996), "The new wave of regional innovation networks: analysis, characteristics and strategy," Small Business Economics, 8 (2), 159-71.

---- (2001), "Regional innovation systems, clusters, and the knowledge economy," Industrial and Corporate Change, 10 (4), 945-74. 
Dacin, M Tina, Kamal A Munir, and Paul Tracey (2010), "Formal dining at Cambridge colleges: Linking ritual performance and institutional maintenance," Academy of Management Journal, 53 (6), 1393-418.

Dahl, Michael S and Olav Sorenson (2012), "Home sweet home: Entrepreneurs' location choices and the performance of their ventures," Management Science, 58 (6), 1059-71.

Dahlstrom, Robert, F Robert Dwyer, and Murali Chandrashekaran (1995), "Environment, structure and performance in interfirm exchange," Journal of Business-to-Business Marketing, 2 (2), 37-58.

Damanpour, Fariborz (1991), "Organizational innovation: A meta-analysis of effects of determinants and moderators," Academy of Management Journal, 34 (3), 555-90.

Deci, Edward L, Richard Koestner, and Richard M Ryan (1999), "A meta-analytic review of experiments examining the effects of extrinsic rewards on intrinsic motivation," Psychological Bulletin, 125 (6), 627-68.

Depner, Heiner and Harald Bathelt (2005), "Exporting the German model: The establishment of a new automobile industry cluster in Shanghai," Economic Geography, 81 (1), 53-81.

Dewar, Robert D and Jane E Dutton (1986), "The adoption of radical and incremental innovations: An empirical analysis," Management Science, 32 (11), 1422-33.

Dhanaraj, Charles and Arvind Parkhe (2006), "Orchestrating innovation networks," Academy of Management Review, 31 (3), 659-69.

Dicken, Peter and Anders Malmberg (2001), "Firms in territories: A relational perspective," Economic Geography, 77 (4), 345-63.

Dyer, Jeffrey $\mathrm{H}$ and Wujin Chu (2003), "The role of trustworthiness in reducing transaction costs and improving performance: Empirical evidence from the United States, Japan, and Korea," Organization Science, 14 (1), 57-68.

Dyer, Jeffrey H and Harbir Singh (1998), "The relational view: Cooperative strategy and sources of interorganizational competitive advantage," Academy of Management Review, 23 (4), 660-79.

Edquist, Charles (1997), Systems of Innovation: Technologies, Institutions and Organisations. London: Pinter.

Eisenhardt, Kathleen M and Behnam N Tabrizi (1995), "Accelerating adaptive processes: Product innovation in the global computer industry," Administrative Science Quarterly, 40 (1), 84-110.

Eisingerich, Andreas B, Simon J Bell, and Paul Tracey (2010), "How can clusters sustain performance? The role of network strength, network openness, and environmental uncertainty," Research Policy, 39 (2), 239-53.

Eppinger, Steven D (2001), "Innovation at the speed of information," Harvard Business Review, 79 (1), 149-58.

Fang, Eric (2008), "Customer participation and the trade-off between new product innovativeness and speed to market," Journal of Marketing, 72 (4), 90-104.

---- (2011), "The effect of strategic alliance knowledge complementarity on new product innovativeness in China," Organization Science, 22 (1), 158-72.

Feser, Edward J and Edward M Bergman (2000), "National industry cluster templates: A framework for applied regional cluster analysis," Regional Studies, 34 (1), 1-19. 
Frigant, Vincent and Yannick Lung (2002), "Geographical proximity and supplying relationships in modular production," International Journal of Urban and Regional Research, 26 (4), 742-55.

Fuchs, Gerhard and Sandra Wassermann (2005), "Path dependency in Baden-Württemberg: Lock-in or breakthrough?," in Rethinking Regional Innovation and Change, Gerhard Fuchs and Philip Shapira, eds. New York: Springer.

Ganesan, Shankar, Alan J Malter, and Aric Rindfleisch (2005), "Does distance still matter? Geographic proximity and new product development," Journal of Marketing, 69 (4), 44-60.

Garnsey, Elizabeth and Paul Heffernan (2005), "High - technology clustering through spin - out and attraction: The Cambridge case," Regional Studies, 39 (8), 1127-44.

Gatignon, Hubert and Jean-Marc Xuereb (1997), "Strategic orientation of the firm and new product performance," Journal of Marketing Research, 34 (1), 77-90.

Gençtürk, Esra F and Preet S Aulakh (2007), "Norms- and control-based governance of international manufacturer-distributor relational exchanges," Journal of International Marketing, 15 (1), 92-126.

Gertler, Meric S (1995), "'Being there': Proximity, organization, and culture in the development and adoption of advanced manufacturing technologies," Economic Geography, 71 (1), 1-26.

Gerwin, Donald (2004), "Coordinating new product development in strategic alliances," Academy of Management Review, 29 (2), 241-57.

Geyskens, Inge, Jan-Benedict E M Steenkamp, and Nirmalya Kumar (2006), "Make, buy, or ally: A transaction cost theory meta-analysis," The Academy of Management Journal, 49 (3), 519-43.

Ghosh, Mrinal and George John (1999), "Governance value analysis and marketing strategy," The Journal of Marketing, 63 (Special Issue), 131-45.

---- (2012), "Progress and prospects for governance value analysis in marketing: When Porter meets Williamson," in Handbook on Business to Business Marketing, Gary L Lilien and Rajdeep Grewal, eds. Cheltenham, UK: Edgar Elgar.

--- (2005), "Strategic fit in industrial alliances: an empirical test of governance value analysis," Journal of Marketing Research, 37 (3), 346-57.

Gibbons, Robert and Rebecca Henderson (2012), "Relational contracts and organizational capabilities," Organization Science, 23 (5), 1350-64.

Gibbons, Robert S (2010), "Inside organizations: Pricing, politics, and path dependence," Annual Review of Economics, 2 (1), 337-65.

Gilson, Ronald J, Charles F Sabel, and Robert E Scott (2009), "Contracting for innovation: Vertical disintegration and interfirm collaboration," Columbia Law Review, 109 (3), 431-502.

Giuliani, Elisa (2007), "The selective nature of knowledge networks in clusters: Evidence from the wine industry," Journal of Economic Geography, 7 (2), 139-68.

Gnyawali, Devi R and Ravindranath Madhavan (2001), "Cooperative networks and competitive dynamics: A structural embeddedness perspective," Academy of Management Review, 26 (3), 431-45.

Granovetter, Mark (1999), "Coase encounters and formal models: Taking Gibbons seriously," Administrative Science Quarterly, 44 (1), 158-62.

---- (1985), "Economic action and social structure: the problem of embeddedness," American Journal of Sociology, 91 (3), 481-510.

---- (1973), "The strength of weak ties," American Journal of Sociology, 78 (6), 1360-80. 
Griffin, Abbie (1997), "The effect of project and process characteristics on product development cycle time," Journal of Marketing Research, 34 (1), 24-35.

Griffin, Abbie and John R Hauser (1996), "Integrating R\&D and marketing: a review and analysis of the literature," Journal of Product Innovation Management, 13 (3), 191-215.

Grossman, Sanford J and Oliver D Hart (1986), "The costs and benefits of ownership: A theory of vertical and lateral integration," The Journal of Political Economy, 94 (4), 691-719.

Gulati, Ranjay and Harbir Singh (1998), "The architecture of cooperation: Managing coordination costs and appropriation concerns in strategic alliances," Administrative Science Quarterly, 43 (4), 781-814.

Hansen, Morten T (1999), "The search-transfer problem: The role of weak ties in sharing knowledge across organization subunits," Administrative Science Quarterly, 44 (1), 82-111.

Hauser, John, Gerard J Tellis, and Abbie Griffin (2006), "Research on innovation: A review and agenda for marketing science," Marketing science, 25 (6), 687-717.

Heath, Chip and Nancy Staudenmayer (2000), "Coordination neglect: How lay theories of organizing complicate coordination in organizations," Research in Organizational Behavior, 22 (1), 153-91.

Heide, Jan B, Kenneth H Wathne, and Aksel I Rokkan (2007), "Interfirm monitoring, social contracts, and relationship outcomes," Journal of Marketing Research, 44 (3), 425-33.

Henderson, Rebecca M and Kim B Clark (1990), "Architectural innovation: The reconfiguration of existing product technologies and the failure of established firms," Administrative Science Quarterly, 35 (1), 9-30.

Hill, Charles WL (1995), "National institutional structures, transaction cost economizing and competitive advantage: The case of Japan," Organization Science, 6 (1), 119-31.

Humphrey, John and Hubert Schmitz (2002), "How does insertion in global value chains affect upgrading in industrial clusters?," Regional Studies, 36 (9), 1017-27.

Independent Commission on Banking (2011), Final Report \& Recommendations. London: The Stationary Office.

Janis, Irving Lester (1982), Groupthink: Psychological Studies of Policy Decisions and Fiascoes. Boston: Houghton Mifflin.

Kaldor, Nicholas (1972), "The irrelevance of equilibrium economics," The Economic Journal, 82 (328), 1237-55.

Keeble, David and Frank Wilkinson (1999), "Collective learning and knowledge development in the evolution of regional clusters of high technology SMEs in Europe," Regional Studies, 33 (4), 295-303.

Kenney, Martin Ed. (2000), Understanding Silicon Valley: The Anatomy of an Entrepreneurial Region. Stanford, CA: Stanford Business Books.

Kilduff, Martin and Wenpin Tsai (2003), Social Networks and Organizations. London: Sage.

Kooijman, Dion and Rypke Sierksma (2007), "Showcase and showroom: automobiles and experience architecture," Journal of Design Research, 6 (4), 509-22.

Koplin, Julia, Stefan Seuring, and Michael Mesterharm (2007), "Incorporating sustainability into supply management in the automotive industry-the case of the Volkswagen AG," Journal of Cleaner Production, 15 (11), 1053-62.

Krugman, Paul R (1991), Geography and Trade. Cambridge, MA: The MIT Press.

Kumar, Alok, Jan B Heide, and Kenneth H Wathne (2011), "Performance implications of mismatched governance regimes across external and internal relationships," Journal of Marketing, 75 (2), 1-17. 
Lassa, Todd (2014), "General Motors restructures its engineering organization," Automobile Magazine, April 22.

Lawson, Clive and Edward Lorenz (1999), "Collective learning, tacit knowledge and regional innovative capacity," Regional Studies, 33 (4), 305-17.

Leslie, Stuart W (2000), "The biggest 'angel' of them all: The military and the making of Silicon Valley," in Understanding Silicon Valley: The Anatomy of an Entrepreneurial Region, M Kenney, ed. Stanford: Stanford University Press.

Li, Julie Juan, Laura Poppo, and Kevin Zheng Zhou (2010), "Relational mechanisms, formal contracts, and local knowledge acquisition by international subsidiaries," Strategic Management Journal, 31 (4), 349-70.

Lyon, Thomas P and Russell A Baruffi (2011), "Creating a plug-in electric vehicle industry cluster in Michigan: Prospects and policy options," Michigan Telecommications \& Technology Law Review, 18 (1), 303-47.

Macaulay, Stewart (1963), "Non-contractual relations in business: A preliminary study," American Sociological Review, 28 (1), 55-67.

Macneil, Ian Roderick (1981), "Economic analysis of contractual relations: Its shortfalls and the need for a 'rich classificatory apparatus'," Northwestern University Law Review, 75 (6), 101863.

Mahmood, Ishtiaq, Chi-Nien Chung, and Will Mitchell (2013), "The evolving impact of combinatorial opportunities and exhaustion on innovation by business groups as market development increases: The case of Taiwan," Management Science, 59 (5), 1142-61.

Markusen, Ann (1996), "Sticky places in slippery space: A typology of industrial districts," Economic Geography, 72 (3), 293-313.

Martin, Ron and Peter Sunley (2003), "Deconstructing clusters: Chaotic concept or policy panacea?," Journal of Economic Geography, 3 (1), 5-35.

McCann, Philip and Stephen Sheppard (2003), "The rise, fall and rise again of industrial location theory," Regional Studies, 37 (6-7), 649-63.

McCarthy, E Jerome (1960), Basic Marketing: A Managerial Approach. Homewood, IL: Richard D. Irwin.

McFadyen, M Ann, Matthew Semadeni, and Albert A Cannella Jr (2009), "Value of strong ties to disconnected others: Examining knowledge creation in biomedicine," Organization Science, 20 (3), 552-64.

McKendrick, David G, Richard F Doner, and Stephan Haggard (2000), From Silicon Valley to Singapore: Location and Competitive Advantage in the Hard Disk Drive Industry. Stanford, CA: Stanford University Press.

Mooi, Erik A and Mrinal Ghosh (2010), "Contract specificity and its performance implications," Journal of Marketing, 74 (2), 105-20.

Moorman, Christine and Anne S Miner (1998), "The convergence of planning and execution: improvisation in new product development," Journal of Marketing, 62 (3), 1-20.

Morgan, Kevin (2004), "The exaggerated death of geography: Learning, proximity and territorial innovation systems," Journal of Economic Geography, 4 (1), 3-21.

Morris, Peter WG, Jeffrey K Pinto, and Jonas Söderlund (2011), "Introduction: Towards the Third Wave of Project Management," in The Oxford Handbook of Project Management, Peter WG Morris and Jeffrey K Pinto and Jonas Söderlund, eds. Oxford: Oxford University Press.

Morrissey, Joseph P, Michael Calloway, W Todd Bartko, M Susan Ridgely, Howard H Goldman, and Robert I Paulson (1994), "Local mental health authorities and service system 
change: Evidence from the Robert Wood Johnson Foundation Program on Chronic Mental Illness," The Milbank Quarterly, 72 (1), 49-80.

Neff, Gina (2005), "The changing place of cultural production: The location of social networks in a digital media industry," The Annals of the American Academy of Political and Social science, 597 (1), 134-52.

North, Douglass C (1987), "Institutions, transaction costs and economic growth," Economic Inquiry, 25 (3), 419-28.

O’Donoghue, Dan and Bill Gleave (2004), "A note on methods for measuring industrial agglomeration," Regional Studies, 38 (4), 419-27.

Obstfeld, David (2005), "Social networks, the tertius iungens orientation, and involvement in innovation," Administrative Science Quarterly, 50 (1), 100-30.

Olson, Eric M, Orville C Walker Jr, and Robert W Ruekert (1995), "Organizing for effective new product development: The moderating role of product innovativeness," The Journal of Marketing, 59 (1), 48-62.

Orsenigo, Luigi (2001), "The (failed) development of a biotechnology cluster: the case of Lombardy," Small Business Economics, 17 (1), 77-92.

Osterloh, Margit and Bruno S Frey (2000), "Motivation, knowledge transfer, and organizational forms," Organization Science, 11 (5), 538-50.

Ouchi, William G (1980), "Markets, bureaucracies, and clans," Administrative Science Quarterly, 25 (1), 129-41.

Owen-Smith, Jason and Walter W Powell (2004), "Knowledge networks as channels and conduits: The effects of spillovers in the Boston biotechnology community," Organization Science, 15 (1), 5-21.

Pfeffer, Jeffrey and Gerald R Salancik (1978), The External Control of Organizations: A Resource Dependence Perspective. New York: Harper \& Row.

Piore, Michael J and Charles F Sabel (1984), The Second Industrial Divide: Possibilities for Prosperity. New York: Basic Books.

Poppo, Laura and Todd R Zenger (2002), "Do formal contracts and relational governance function as substitutes or complements?," Strategic Management Journal, 23 (8), 707-25.

Porter, Michael (2000), "Location, clusters and economic strategy," in The Oxford Handbook of Economic Geography, G.L. Clark and M. Feldman and M.S. Gertler, eds. Oxford: Oxford University Press.

Porter, Michael E (1998), Clusters and Competition: New Agendas for Companies, Governments, and Institutions. Boston: Harvard Business School Press.

Provan, Keith G, Amy Fish, and Joerg Sydow (2007), "Interorganizational networks at the network level: A review of the empirical literature on whole networks," Journal of Management, 33 (3), 479-516.

Provan, Keith G and Patrick Kenis (2008), "Modes of network governance: Structure, management, and effectiveness," Journal of Public Administration Research and Theory, 18 (2), $229-52$.

Ramasamy, Bala, Anita Chakrabarty, and Madeleine Cheah (2004), "Malaysia's leap into the future: An evaluation of the multimedia super corridor," Technovation, 24 (11), 871-83.

Rindfleisch, Aric and Christine Moorman (2001), "The acquisition and utilization of information in new product alliances: A strength-of-ties perspective," The Journal of Marketing, $65(2), 1-18$. 
Rodan, Simon and Charles Galunic (2004), "More than network structure: How knowledge heterogeneity influences managerial performance and innovativeness," Strategic Management Journal, 25 (6), 541-62.

Romanelli, Elaine and Olga M Khessina (2005), "Regional industrial identity: Cluster configurations and economic development," Organization Science, 16 (4), 344-58.

Rowley, Tim, Dean Behrens, and David Krackhardt (2000), "Redundant governance structures: An analysis of structural and relational embeddedness in the steel and semiconductor industries," Strategic Management Journal, 21 (3), 369-86.

Rowley, Timothy J (1997), "Moving beyond dyadic ties: A network theory of stakeholder influences," Academy of management Review, 22 (4), 887-910.

Sako, Mari (2004), "Supplier development at Honda, Nissan and Toyota: Comparative case studies of organizational capability enhancement," Industrial and Corporate Change, 13 (2), 281-308.

Scott, Allen J (1988), "Flexible production systems and regional development: The rise of new industrial spaces in North America and western Europe," International Journal of Urban and Regional Research, 12 (2), 171-86.

Sethi, Rajesh, Daniel C Smith, and C Whan Park (2001), "Cross-functional product development teams, creativity, and the innovativeness of new consumer products," Journal of Marketing Research, 38 (1), 73-85.

Simon, Herbert A (1985), "Human nature in politics: The dialogue of psychology with political science," The American Political Science Review, 79 (2), 293-304.

Sivadas, Eugene and F Robert Dwyer (2000), "An examination of organizational factors influencing new product success in internal and alliance-based processes," The Journal of Marketing, 64 (1), 31-49.

Sobrero, Maurizio and Edward B Roberts (2001), "The trade-off between efficiency and learning in interorganizational relationships for product development," Management Science, 47 (4), 493-511.

Sosa, Manuel E (2007), "Aligning process, product, and organizational architectures in software development," International Conference on Engineering Design, Paris, August 20-31.

---- (2014), "Realizing the need for rework: From task interdependence to social networks," Production and Operations Management, Forthcoming.

Sosa, Manuel E, Steven D Eppinger, and Craig M Rowles (2004), "The misalignment of product architecture and organizational structure in complex product development,"

Management Science, 50 (12), 1674-89.

Staudenmayer, Nancy, Mary Tripsas, and Christopher L Tucci (2005), "Interfirm modularity and its implications for product development," Journal of Product Innovation Management, 22 (4), 303-21.

Stinchcombe, Arthur L (1986), "Norms of exchange," in Stratification and Organization: Selected Papers, A.L. Stinchcombe, ed. Cambridge: Cambridge University Press.

Suchman, Mark C and Mia L Cahill (1996), "The hired gun as facilitator: Lawyers and the suppression of business disputes in Silicon Valley," Law \& Social Inquiry, 21 (3), 679-712.

Taber, George M (2009), To Cork or Not to Cork. New York, NY: Simon and Schuster.

Tallman, Stephen, Mark Jenkins, Nick Henry, and Steven Pinch (2004), "Knowledge, clusters, and competitive advantage," Academy of Management Review, 29 (2), 258-71.

Tallman, Stephen and Anupama Phene (2007), "Leveraging knowledge across geographic boundaries," Organization Science, 18 (2), 252-60. 
Tellis, Gerard J (2013), Unrelenting Innovation: How to Build a Culture for Market Dominance. San Francisco, CA: Jossey-Bass.

Tellis, Gerard J , Rajesh K Chandy, and Jaideep C Prabhu (2012), "Key questions on innovation in the B2B context," in Handbook of Business-to-Business Marketing, G L Lilien and R Grewal, eds. Cheltenham, UK: Edgar Elgar.

Terwiesch, Christian, Christoph H Loch, and Arnoud De Meyer (2002), "Exchanging preliminary information in concurrent engineering: Alternative coordination strategies," Organization Science, 13 (4), 402-19.

Thompson, James D (1967), Organizations in Action: Social science Bases of Administrative Theory. New York, NY: McGraw-Hill.

Tuli, Kapil R, Sundar G Bharadwaj, and Ajay K Kohli (2010), "Ties that bind: The impact of multiple types of ties with a customer on sales growth and sales volatility," Journal of Marketing Research, 47 (1), 36-50.

Ulrich, Karl T and Steven D Eppinger (2011), Product Design and Development (5th ed.). New York, NY: McGraw-Hill.

Ulset, Svein (1996), "R\&D outsourcing and contractual governance: An empirical study of commercial R\&D projects," Journal of Economic Behavior \& Organization, 30 (1), 63-82.

Uzzi, Brian (1997), "Social structure and competition in interfirm networks: The paradox of embeddedness," Administrative Science Quarterly, 42 (1), 35-67.

---- (1996), "The sources and consequences of embeddedness for the economic performance of organizations: The network effect," American Sociological Review, 42 (1), 674-98.

Van Hoek, Remko I and Harm A M Weken (1998), "The impact of modular production on the dynamics of supply chains," The International Journal of Logistics Management, 9 (2), 3550 .

Venkataraman, S (1997), "The distinctive domain of entrepreneurship research: An editor's perspective," in Advances in Entrepreneurship, Firm Emergence and Growth, J Katz and R H Brockhaus, eds. Greenwich: JAI Press.

Von Hippel, Eric (1994), "“Sticky information" and the locus of problem solving: implications for innovation," Management Science, 40 (4), 429-39.

Wang, Qiong, Kevin Bradford, Jun Xu, and Barton Weitz (2008), "Creativity in buyer-seller relationships: The role of governance," International Journal of Research in Marketing, 25 (2), 109-18.

Wasserman, Stanley and Katherine Faust (1994), Social Network Analysis: Methods and Applications. Cambridge: Cambridge University Press.

Wasserman, Stanley and Joseph Galaskiewicz (1994), Advances in social network analysis: Research in the social and behavioral sciences. London: Sage.

Wathne, Kenneth H and Jan B Heide (2000), "Opportunism in interfirm relationships: Forms, outcomes, and solutions," The Journal of Marketing, 64 (4), 36-51.

---- (2004), "Relationship governance in a supply chain network," Journal of Marketing, 68 (1), 73-89.

Weber, M (1947), Theory of Social and Economic Organization. New York: The Free Press.

Wheelwright, Steven C and Kim B Clark (1992), Revolutionizing Product Development: Quantum Leaps in Speed, Efficiency, and Quality. New York, NY: The Free Press.

Whittam, Geoff and Mike Danson (2001), "Power and the spirit of clustering," European Planning Studies, 9 (8), 949-63. 
Whittington, Kjerston B, Jason Owen-Smith, and Walter W Powell (2009), "Networks, propinquity, and innovation in knowledge-intensive industries," Administrative Science Quarterly, 54 (1), 90-122.

Williamson, Oliver E (2000), "The new institutional economics: Taking stock, looking ahead," Journal of Economic Literature, 38 (3), 595-613.

---- (2010), "Transaction cost economics: The natural progression," The American Economic Review, 100 (3), 673-90.

Wuyts, Stefan and Inge Geyskens (2005), "The formation of buyer-supplier relationships: Detailed contract drafting and close partner selection," Journal of Marketing, 69 (4), 103-17.

Wuyts, Stefan and Christophe Van den Bulte (2012), "Network governance," in Handbook on Business to Business Marketing, G L Lilien and R Grewal, eds. Cheltenham, UK: Edgar Elgar. 


\section{Figure 1 - Conceptual Model}

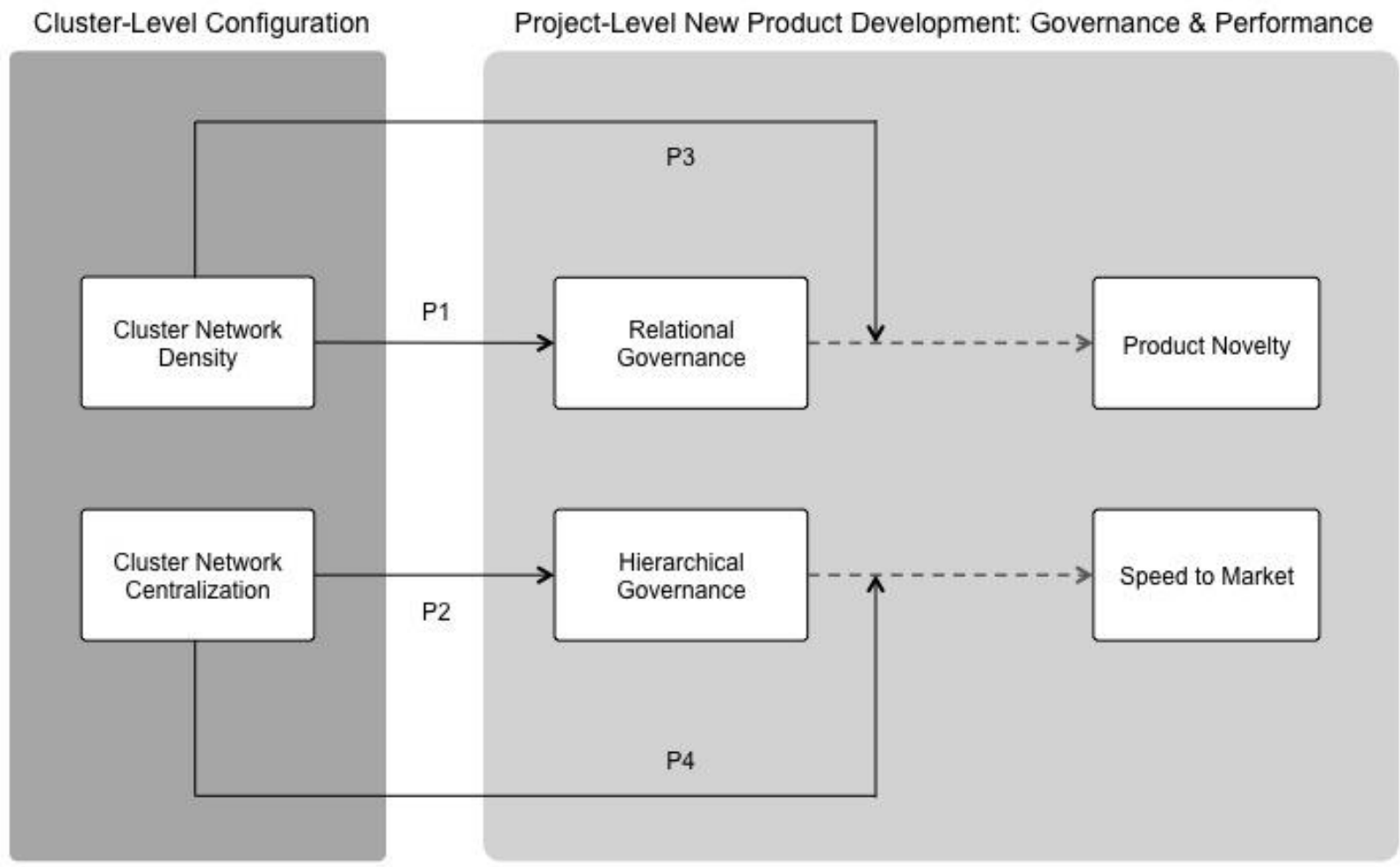

Baseline effects of governance on performance

Hypothesized effects 